Heyningen, W. E. van (1951). J. gen. Microbiol. 5, 758-765.

\title{
The Antibacterial Activity of Haematin
}

\author{
By W. E. VAN HEYNINGEN \\ Sir William Dunn School of Pathology, University of Oxford
}

SUMMARY: Haematin in concentrations of $1 / 1,000,000-1 / 2,000,000$ inhibited the growth of a number of bacteria most of which were aerobic sporing bacilli. Deuterohaematin and mesohaematin were also inhibitory, but not haematohaematin, urohaematin and a number of iron-free porphyrin derivatives. In a few cases whole blood was inhibitory, but generally only trypsin-digested laked red cells. The mechanism of the antibacterial activity is not understood.

This work arises from an observation by Dr R. L. Vollum that a culture of Bacillus subtilis appeared to autolyse very readily when grown on a bloodagar plate. It was thought that this observation might throw light on the mechanism of bacterial autolysis, but further investigation showed that autolysis was only a secondary result of the antibacterial action of haematin liberated from the blood.

These are not the first observations on the antibacterial activity of ironporphyrins. While this work was in progress Professor Rimington pointed out that many years ago Kämmerer (1914) made the interesting observation that mesohaematin (i.e. haematin with the two vinyl groups reduced) was inhibitory to a large number of Gram-positive bacteria, including aerobic sporing bacilli, staphylococci, streptococci, pneumococci and corynebacteria. $B$. anthracis was inhibited by concentrations of $1 / 500,000$. He believed that the antibacterial action of mesohaematin exceeded that of many antiseptics such as Karbol and Lysol, and was comparable with that of corrosive sublimate. Kämmerer did not observe any antibacterial activity of haematin, except in concentrations as high as $1 / 300$; at $1 / 2,000$ it tended to stimulate the growth of his test organisms.

Glass (1939) observed that haematin at a concentration of $1 / 100,000$ was inhibitory to certain mitis strains of Corynebacterium diphtheriae.

\section{METHODS}

Bacterial growth in liquid cultures was determined by measuring the optical density (D) of the cultures with a photoelectric densitometer. D is the logarithm of the ratio of the incident light to the light transmitted through $1 \mathrm{~cm}$. of the bacterial suspension. The values for $\mathbf{D}$ were translated into mg. dry weight organism $/ \mathrm{ml}$. by means of an experimentally determined standard curve. Corrections were made for the optical densities of uninoculated media. The cultures were grown in shallow layers of medium which were continuously agitated.

Proteolytic activity of bacterial cultures was determined in gelatin stabs and also by stabbing cultures into a $2 \%$ suspension of casein in nutrient agar 
poured in Petri dishes. After $48 \mathrm{hr}$. incubation proteolytic colonies were surrounded by clear transparent zones in a white opaque matrix of undigested casein.

Succinic oxidase activity of washed cultures was judged by measuring the reduction time of methylene blue in the presence of succinate in Thunberg tubes. Bacterial respiration was measured in the usual way with Warburg manometers. $\mathrm{pH}$ values were determined electrometrically with a glass electrode.

\section{RESULTS}

\section{Effect of blood on the growth of aerobic sporing bacilli}

Petri dishes were poured with nutrient agar and after cooling a half-circle of the agar was removed and replaced by agar containing $\mathbf{1 . 5} \%$ horse blood. The plates were then spread with an inoculum of $B$. subtilis and incubated at $37^{\circ}$. After $12 \mathrm{hr}$. incubation the organism had grown lightly and evenly on both halves of the plate. After $24 \mathrm{hr}$. the organisms on the blood agar were completely autolysed while the growth on the other half of the plate was profuse and normal. The organisms on this half eventually autolysed after 4-6 days. Whole blood could be replaced with washed red cells, which were more effective when laked with distilled water. Plasma had no effect. The effect with whole red cells could be obtained with only 6 out of 35 strains of $B$. subtilis that were tested, and with none of 19 strains of $B$. licheniformis. With laked red cells a few more strains of $B$. subtilis were affected.

When trypsin (25 $\mu \mathrm{g}$. crystals/ml.) was incorporated in the laked red cell agar the effect was changed qualitatively and quantitatively. Instead of growing and then rapidly autolysing, the organism failed to grow at all. Moreover, inhibition of growth was now caused by a much lower concentration of laked red cells and affected all 35 strains of $B$. subtilis and all 19 strains of B. licheniformis. Control experiments showed that trypsin itself had no observable effect on these organisms. Strains of $B$. subtilis fell into at least four groups (Table 1) as far as their behaviour towards red blood cells was

Table 1. Differences in inhibition of growth of different groups of strains of B. subtilis by treated and untreated red cells

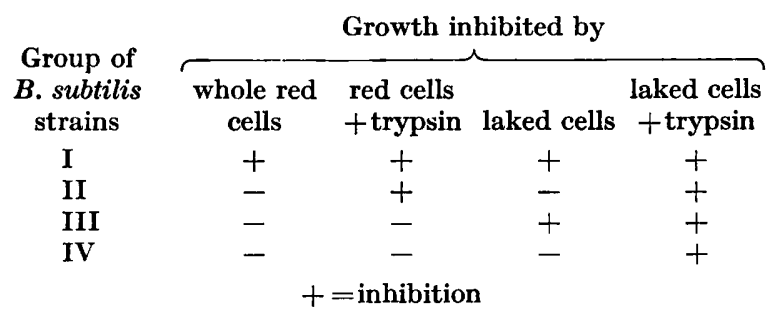

concerned, but they were not always consistent in their behaviour; after being stored in the cold for several months strains from group IV behaved like those from group II. The differences in behaviour of groups I and IV 
could be due to differences in their sensitivity to the inhibitory substance, or to differences in their production of proteolytic enzymes. Strains from groups I and IV were tested for their sensitivity to the inhibitory substance (which had been shown to be haematin) and they did not differ markedly, nor was there any obvious difference in their proteolytic activity against gelatin or casein. On the other hand, strains of $B$. licheniformis, which all behaved towards red cells like group IV $B$. subtilis strains, were less proteolytic towards these substrates than $B$. subtilis. It is difficult to see how differences in sensitivity or protease production could account for the fact that laked cells were more effective than trypsin-treated cells for strains of groups I and III, and less effective for group II. These differences are also apparent in Pl. 1, where in dish 1 the inhibition zone at $D$ (laked cells) is greater than that at $\mathrm{C}$ (whole red cells + trypsin), but in dish 2 the reverse is true.

Some group IV strains were haemolytic, but they were inhibited only by laked red cells +trypsin, and not by haemolysed cells +trypsin. A possible explanation for this is that the cells were not haemolysed until the organisms were fully grown and therefore less sensitive to the action of haematin.

Pl. 1, dish 2, suggests that red blood cells contain a slowly diffusible stimulatory substance as well as a more rapidly diffusible inhibitory substance. There is growth on all the plugs, but those in which the inhibitory substance has been released by trypsin are surrounded by zones of inhibition. In the plugs themselves the concentration of stimulatory substance is sufficient to counteract the inhibitory substance.

It seems clear that the effect of blood on $B$. subtilis is not directly to cause it to autolyse, but to inhibit its growth. When intact red cells are used the inhibitory substance is released slowly, so that the organism has time to grow. But after a time a sufficient concentration of the inhibitory substance is released to stop the growth of the organisms, which then autolyse. It is known that $B$. subtilis autolyses readily when its growth ceases. When the inhibitory substance is released from laked cells by trypsin the organisms are inhibited immediately and they fail to grow.

\section{The antibacterial activity of haematin}

Since the inhibitory substance was liberated from red cells by proteolytic enzymes, and since concentrates of the substance were dark-coloured it was thought that it might be haem. Haemin was, therefore, prepared from laked ox blood by the method of Fischer \& Orth (1937) and purified. The purified product was dissolved in dilute $\mathrm{NaOH}$ and its inhibitory effect tested on cultures of $B$. subtilis in potato dextrose medium (Arriagada et al. 1949) at $\mathrm{pH} 7 \cdot 5$ (where it is in the form of haematin). A concentration of $1 / 2,000,000$ inhibited the growth of an inoculum (loopful of an overnight culture) of $\boldsymbol{B}$. subtilis, but at this concentration the inhibition was only temporary and amounted to a prolongation of the lag-phase by several hours. At 1/1,000,000 it generally, but not always, prevented an inoculum from growing. Higher concentrations of haematin were needed to inhibit growing cultures (Fig. 1). 
To observe the full effect of haematin it was necessary to avoid heating it in the presence of complex media. When it was autoclaved in heart broth or heart agar the concentration that was inhibitory to an inoculum of $B$. subtilis generally rose to about $1 / 40,000$, and sometimes to $1 / 10,000$. Autoclaving haematin in the presence of synthetic media had a much smaller effect.

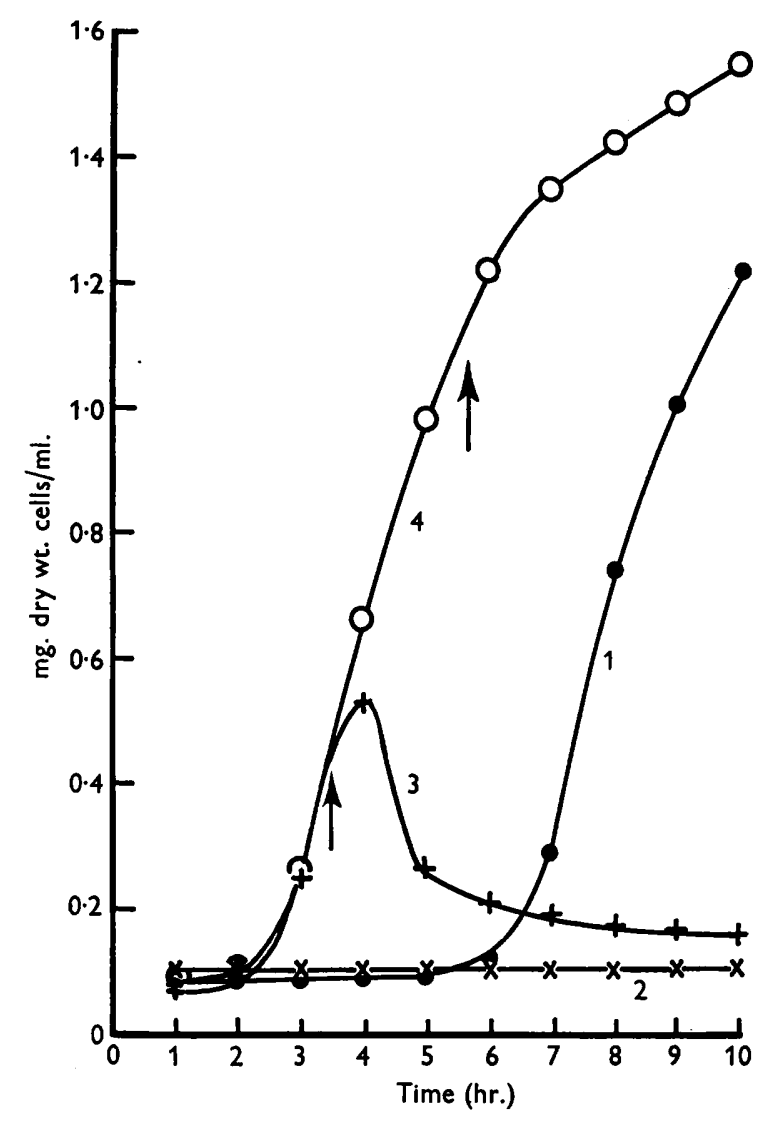

Fig. 1. Inhibition of growth of $B$. subtilis in potato glucose medium by haematin. Curve 1, 1/2,000,000 haematin added before inoculation; Curve 2, 1/1,000,000 haematin added before inoculation; Curve $3,1 / 250,000$ haematin added $3.5 \mathrm{hr}$. after inoculation; Curve 4, 1/250,000 haematin added $5 \cdot 5 \mathrm{hr}$. after inoculation.

The effect of haematin on other aerobic sporing bacilli was tested by streaking them (3 or 4 at a time) on plates containing adjacent half-circles of plain heart agar and heart agar containing 1/30,000 haematin (added to the molten agar at $47^{\circ}$ ). The results of these experiments are shown in Table 2. In a preliminary report (van Heyningen, 1948) it was stated that B. anthracis, $B$. laterosporus, and $B$. alvei were not inhibited by $1 / 20,000$ haematin, but in those experiments the haematin was autoclaved in the nutrient agar.

At a concentration of $1 / 20,000$ haematin did not inhibit the following 
organisms: Bacterium lactis aerogenes, Bact. coli, Bact. friedländeri, Chromobacterium prodigiosum, Micrococcus tetragenus, Mycobacterium phlei, Mycobact. smegmatis, Proteus vulgaris, Salmonella paratyphi A \& B, Salm. typhi H \& O, Sarcina lutea, Shigella flexneri, Sh. sonnei, Sh. shigae, Staphylococcus albus, Staph. aureus, Vibrio cholerae, El Tor vibrio. At a concentration of 1/20,000 haematin completely inhibited two mitis strains and one gravis strain of C. diphtheriae, and partially inhibited one strain each of C. hofmanni and $C$. xerosis. On the other hand, it strongly stimulated the growth of two strains of starch-fermenting, gelatin-liquifying corynebacteria.

Table 2. Inhibition of aerobic sporing bacilli by haematin $(1 / 30,000)$

\begin{tabular}{|c|c|c|c|c|c|}
\hline Organism & $\begin{array}{l}\text { Number of } \\
\text { strains } \\
\text { tested }\end{array}$ & $\begin{array}{l}\text { Completely } \\
\text { inhibited }\end{array}$ & $\begin{array}{l}\text { Partially } \\
\text { inhibited }\end{array}$ & $\begin{array}{c}\text { Not } \\
\text { inhibited }\end{array}$ & $\begin{array}{c}\text { Growth } \\
\text { on control } \\
\text { agar }\end{array}$ \\
\hline B. alvei & 8 & 8 & $\mathbf{0}$ & $\mathbf{0}$ & + \\
\hline B. brevis & 12 & 7 & 4 & 1 & + \\
\hline B. circulans & 10 & 7 & 3 & 0 & + \\
\hline B. laterosporus & 3 & 3 & $\mathbf{0}$ & $\mathbf{0}$ & + \\
\hline B. licheniformis & 19 & 19 & 0 & 0 & $+++t$ \\
\hline B. macerans & 3 & 3 & $\mathbf{0}$ & $\mathbf{0}$ & + \\
\hline B. polymyxa & 1 & 1 & $\mathbf{0}$ & $\mathbf{0}$ & + \\
\hline B. pumilus & 5 & $\mathbf{5}$ & $\mathbf{0}$ & 0 & ++++ \\
\hline B. subtilis & 35 & 35 & $\mathbf{0}$ & $\mathbf{0}$ & $+t+t$ \\
\hline B. anthracis & 2 & $\mathbf{0}$ & 2 & $\mathbf{0}$ & ++++ \\
\hline B. megatherium & 7 & $\mathbf{0}$ & 7 & 0 & ++++ \\
\hline B. carotarum & 7 & $\mathbf{0}$ & $\mathbf{2}$ & $\mathbf{5}$ & $++t+$ \\
\hline B. cereus & 16 & 1 & 2 & 13 & $++t+$ \\
\hline B. firmus & 1 & $\mathbf{0}$ & $\mathbf{0}$ & $\mathbf{1}$ & $++t+$ \\
\hline B. fusiformis & 7 & $\mathbf{0}$ & 3 & 4 & $+t+t$ \\
\hline B. mycoides & 5 & 0 & 0 & 5 & ++++ \\
\hline
\end{tabular}

The effect of a number of porphyrin and iron-porphyrin derivatives at a concentration of $1 / 20,000$ was tested on $B$. anthracis, $B$. brevis, B. cereus, $B$. licheniformis, $B$. megatherium and $B$. subtilis, with the results shown in Table 3. These results suggest that mesohaematin is the most active of the compounds tested and that the presence of an iron atom in the molecule is essential for inhibitory activity. They also lead to the tentative conclusion that a non-polar group in positions 2 and 4 is necessary for inhibitory activity.

Keilin \& Hartree (1947) found that deuterohaematin, haematin and haematohaematin at a concentration of $2 \times 10^{-4} \mathrm{M}$ almost completely inhibited the oxidation of succinic acid by highly active muscle preparations. The enzyme could be protected from this inhibitory effect by the prior addition of glyoxalin or denatured protein and they concluded that the inhibition was due to the formation of a co-ordination compound between the haematin iron and some groups in succinic dehydrogenase important for its activity. In view of this the effect of haematin $(1 / 5,000)$ on the succinic oxidase systems of washed suspensions of $B$. subtilis, B. cereus, B. licheniformis and B. mycoides was tested, but no conclusive results were obtained. Inhibition of oxidase 


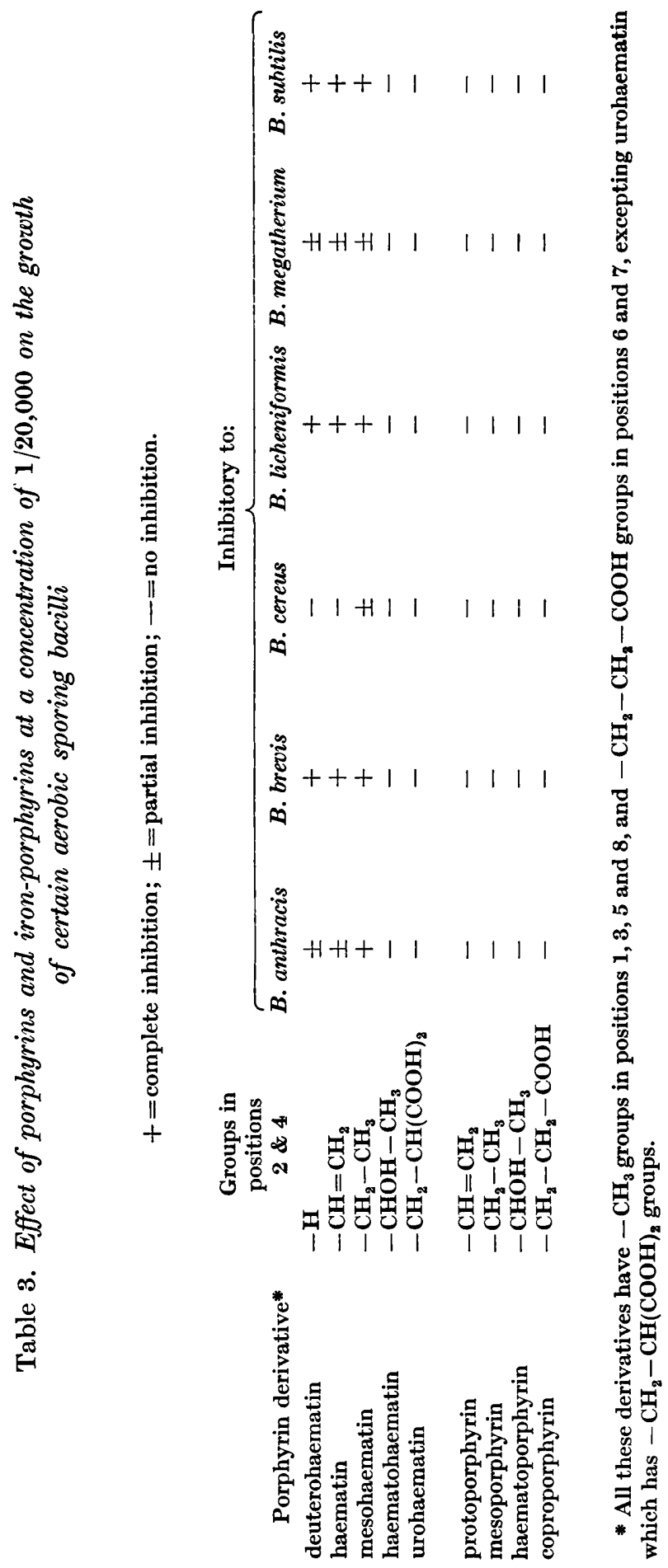


activity was observed, but it was very variable, and the organisms (B. subtilis and $\boldsymbol{B}$. licheniformis) whose growth was inhibited by haematin were no more affected than those (B. cereus and B. mycoides) whose growth was not inhibited.

The effect of haematin on the respiration of these organisms was also examined. No inhibition of respiration was observed with haematin at a concentration of $1 / 50,000$, but at $1 / 5,000$ inhibition was complete, whether

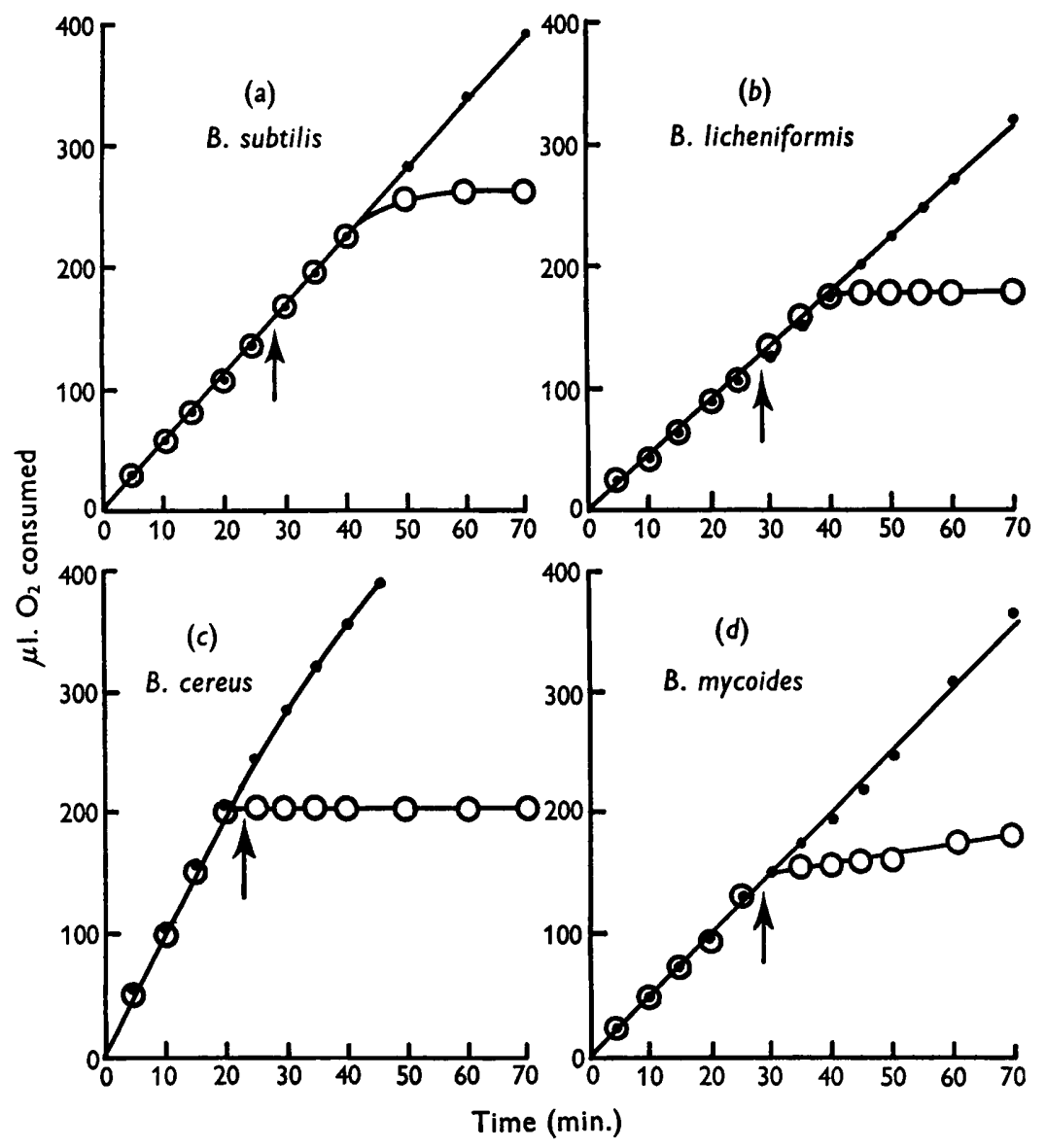

FIG. 2. Effect of haematin (1/5,000 final concentration) on respiration of organisms whose growth is inhibited by haematin $(a \& b)$ and whose growth is not inhibited by haematin $(c \& d)$. Haematin added at times indicated by arrows.

or not the growth of the organisms was inhibited by haematin. The only difference that could be seen was that with organisms whose growth was inhibited (B. licheniformis and $\boldsymbol{B}$. subtilis) there was a lag period of about $15 \mathrm{~min}$. between the addition of the haematin and the cessation of respiration, whereas with those whose growth was not inhibited (B. cereus and B. mycoides) the inhibition was immediate (Fig. 2). Superficially, at any rate, this was the reverse of what might have been expected. In control experiments the respiration of Bact. coli was unaffected by $1 / 5,000$ haematin. 

Journal of General Microbiology, Vol. 5, No. 4

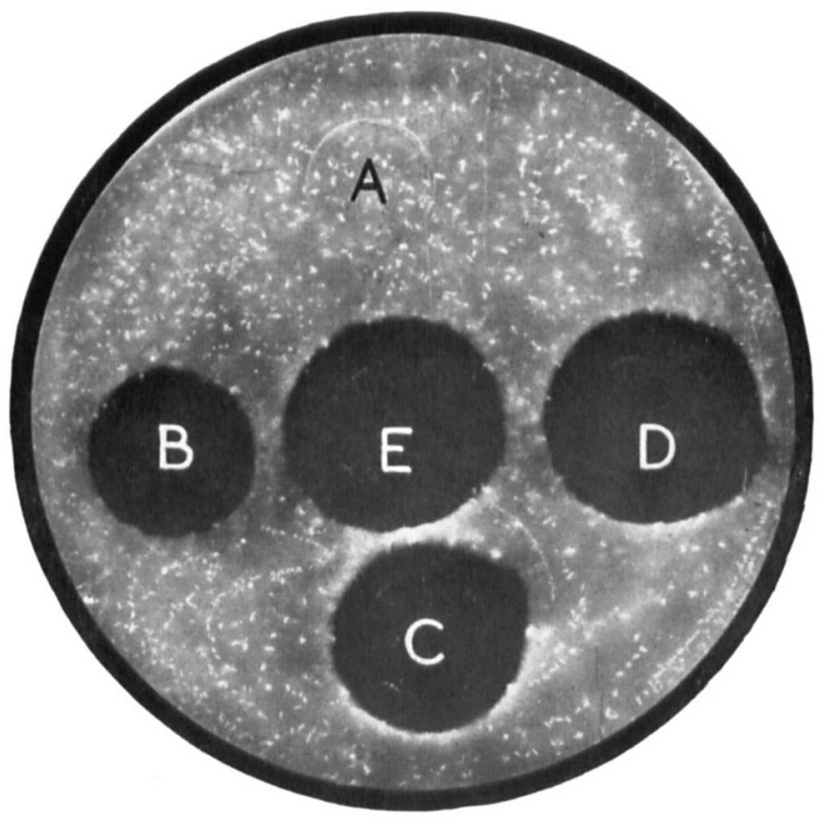

Dish 1

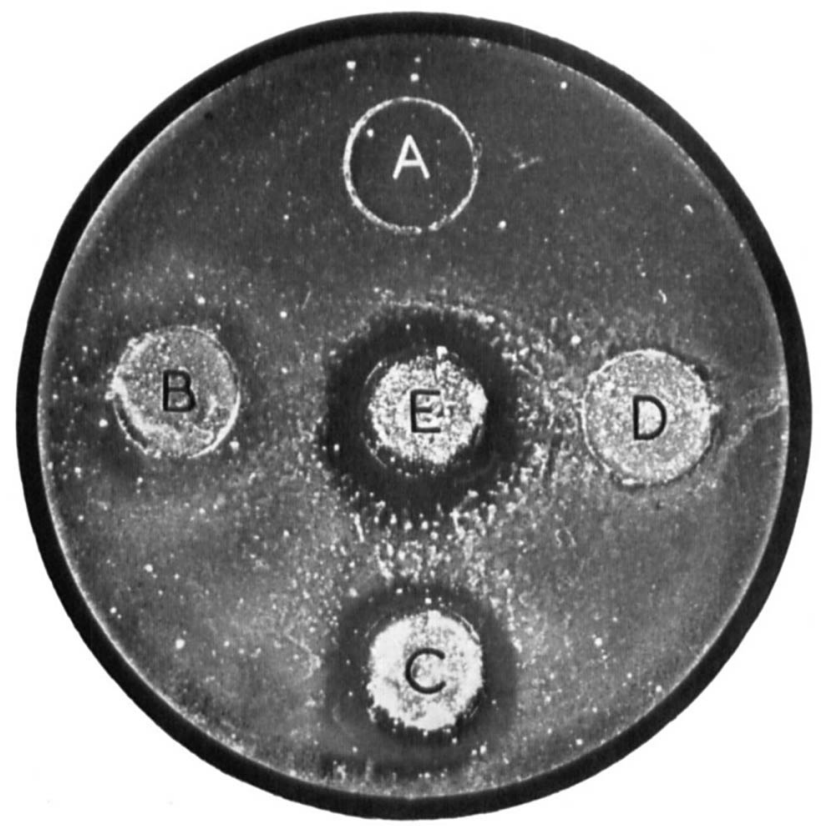

Dish 2

W. E. van Heyningen-The Antibacterial Activity of Haematin. Plate 1 


\section{DISCUSSION}

The results reported in this paper confirm Kämmerer's interesting observations in so far as mesohaematin was found to be antibacterial and to have a greater activity than haematin. It is possible that the inactivity of haematin in Kämmerer's experience may have been due to his autoclaving this substance in his nutrient medium.

Anigstein, Whitney \& Micks (1950) (see also Whitney, Anigstein \& Micks, 1950 ) reported that tryptic digests of ticks are inhibitory to a number of species of bacteria, the aerobic sporing bacilli being the most sensitive. The antibacterial activity of extracts of ticks engorged with blood was considerably enhanced, and the inhibitory substance was shown to be associated with red blood cells. They suggest that the inhibitory substance is a peptide, but it is more likely to be haematin.

I am grateful to Dr Kathleen Crawford for strains of aerobic sporing bacilli, to Professor Rimington and Dr Joan Keilin for porphyrin derivatives, and to Miss Winifred Crawford for technical assistance.

\section{REFERENCES}

Anigstein, L., Whitney, D. M. \& Micks, D. W. (1950). Antibacterial activity of a substance present in ticks (ixodoidea) of Texas. Nature, Lond., 166, 141-3.

Arriagada, A., Savage, M. C., Abraham, E. P., Heatley, N. G. \& Sharp, A. E. (1949). Ayfivin, an antibiotic from B. licheniformis. Production in potato dextrose medium. Brit. J. exp. Path. 30, 425-7.

Fischer, H. \& Orth, H. (1937). Die Chemie des Pyrrols II. Leipzig. Akademische Verlagsgesellschaft m.b.H. p. 377.

Grass, V. (1939). The effect of blood digest and haem on the growth of C. diphtheriae. J. Path. Bact. 49, 549.

Heyningen, W. E. van (1948). Inhibition of aerobic sporing bacilli by haematin. Nature, Lond., 162, 114.

Kämmerer, H. (1914). Das Verhalten von Bakterien gegen einige BlutfarbstoffDerivate. Verh. dtsch. Kongr. inn. Med. 31, 704.

Keilin, D. \& Hartree, E. F. (1947). Effect of haematin on the oxidation of succinic acid by tissue preparations. Biochem. J. 41, 503.

Whitney, D. M., Anigstein, L. \& Mrcks, D. W. (1950). Antibacterial activity of hydrolysed red blood cells in vitro. Proc. Soc. exp. Biol. N.Y., 74, 346.

\section{EXPLANATION OF PLATE}

Pl. 1. Differences in inhibition of two strains of $B$. subtilis by red cells. Holes in nutrient agar plugged with agar containing: A, 25 $\mu \mathrm{g}$. trypsin $/ \mathrm{ml}$.; B, 3\% washed horse red cells; C, $3 \%$ red cells $+25 \mu$ g. trypsin $/ \mathrm{ml}$.; D, $3 \%$ laked red cells; $\mathrm{E}, 3 \%$ laked red cells $\times 25 \mu$ g. trypsin $/ \mathrm{ml}$.

Dish 1 flooded with inoculum from group $\mathbf{I}$ (see Table 1 ).

Dish 2 flooded with inoculum from group II.

The agar in both dishes contained $0.03 \%$ Neutral Red in order to simplify the photography of dishes containing red plugs. In dish 1 some of the Neutral Red has crystallized out. 